\title{
A Wavelet-based Algorithm for the Computation of Intraseasonal Oscillations Intensity and Frequency Indices and Application to Central Africa
}

\author{
Alain Tchakoutio Sandjon ${ }^{1,2,3, *}$, Armand Nzeukou Takougang ${ }^{3}$ \\ ${ }^{1}$ Laboratory of Environmental Modeling and Atmospheric Physics, University of Yaoundé I, Yaoundé, Cameroon \\ ${ }^{2}$ Department of Computer Science Including Basic Sciences, Higher Technical Teacher's Training College Kumba, University of Buea, \\ Kumba, Cameroon \\ ${ }^{3}$ Laboratory of Industrial Systems and Environmental Engineering, Fotso Victor University Institute of Technology, University of Dschang, \\ Bandjoun, Cameroon
}

Email address:

stchakoutio@yahoo.com (A. T. Sandjon)

${ }^{*}$ Corresponding author

\section{To cite this article:}

Alain Tchakoutio Sandjon, Armand Nzeukou Takougang. A Wavelet-based Algorithm for the Computation of Intraseasonal Oscillations Intensity and Frequency Indices and Application to Central Africa. International Journal of Environmental Monitoring and Analysis. Vol. 8, No. 4, 2020, pp. 111-116. doi: 10.11648/j.ijema.20200804.14

Received: May 19, 2020; Accepted: July 7, 2020; Published: August 31, 2020

\begin{abstract}
The rainfall modeling at regional scale remains a great challenge in the tropics because of the complexity of the processes that induce rainfall variability. Then the good parameterization of some atmospheric processes will be of great contribution towards the improvement of regional models. In this paper we applied wavelet transform on $2.5^{\circ} \times 2.5^{\circ}$ daily Outgoing Long-wave Radiation (OLR) datasets for the period 1981-2015 (35 years) to extract Intraseasonal Intensity (ISOI) and intraseasonal Period (ISOP), with application to Central Africa (CA). In fact for each grid point in the study area, the wavelet transform was applied to the 25-70-day filtered daily OLR time series and the wavelet spectrum is obtained. In the resulting spectrum, the maximum variance for each day is taken as ISOI and the period exhibiting that maximum variance is the ISOP. The plots of seasonal mean ISOI and ISOP obtained showed that the ISO characteristics (amplitude, frequency) strongly vary from season to another. The ISO amplitude is extremely high during December-February (DJF) and March-May (MAM) and lower during JJA and SON seasons. As for the period of oscillations, the ISOP peaks during MAM and JJA seasons. But for the four seasons, the period is predominantly contained between 40-50 days, suggesting the dominance of Madden-Julian Oscillation (MJO) signal.
\end{abstract}

Keywords: Intraseasonal Oscillations, Central Africa, Wavelets Analysis, Intensity, Frequency

\section{Introduction}

Rainfall variability in Africa at different timescales will continue to draw the attention of many researchers around the world. In fact the high instability observed in the rainfall regime in the tropics during the recent years led researchers to better study some atmospheric phenomena more deeply in order to explain these fluctuations in terms of amount and distribution of rainfall [1-6]. Moreover rainfall is of great importance in tropical Africa because the population is mostly rural and therefore their main sources of incomes such as rainfed agriculture, livestock and fishing are strongly based on rainfall. So the distribution of rain within the season is very important for the planning of agro-pastoral activities in these regions.

Before the 1960 s, it was very difficult to carry out studies on rainfall variability at a shorter timescales because of the low temporal resolution of the available data, which were most often monthly or annual datasets. Most of studies on rainfall variability addressed the annual cycle of rainfall as well as the interannual variability. But since the advent of satellite measurements in the beginning 1970s, many datasets are available at very good spatial and temporal resolutions, up to the hourly scale for some satellite products [7-10]. The 
notion of intraseasonal scale then appeared in the scientific community and many researchers then investigated the intraseasonal variability of some atmospheric fields around the world [11-15]. In the tropics rainfall is among atmospheric variables, one of those which are very difficult to predict because of their high spatio-temporal variations. To improve understanding of the distribution and variability of rainfall as well as its forecast, many researchers studied the intra-seasonal variability of rainfall in several regions across the tropics $[12,14]$.

However Central Africa $\left(15^{\circ} \mathrm{S}-15^{\circ} \mathrm{N}, 0-50^{\circ} \mathrm{E}\right)$ remains a region whose climate is poorly understood because the majority of studies carried out in Africa at intraseasonal time scales have been biased towards West or East Africa [12, 13, 15-16]. Very few of these studies focused mainly on Central Africa (CA). Indeed climatologically speaking, CA is a very complex region because of its geographical location, as well as its topography and vegetation. CA undergoes influence of the fluxes coming from the Atlantic Ocean at the West boundary and the Indian Ocean at its East boundary. The topography of the region is quite various, including Highlands, mountains, Plateaus. The western Central Africa (west of Rift valley) is almost covered by the Congo forest, which keeps this region quite wet within the year. Rainfall is highly seasonal as can be expected from its tropical location. The Eastern part (east of Rift valley) is characterized by widely varied vegetation ranging from desert to forest over relatively small areas. Very few authors investigated the intraseasonal rainfall variability in CA and they found that the dominant mode of intraseasonal variability is MJO with period around 30-60 days. They also found that ISO activity in CA undergoes high annual and interannual variations [1719].

In the study of variations in the intensity and frequency of ISO, many authors used the average signal at global or regional scales. They generally used the principal component analysis to extract the dominant modes of intra-seasonal variability over the area and computed the ISOI from the first two or three principal components (e.g. $[14,20])$. But this approach could not allow us to get information about the local variations of the ISO signal. However in the regions like CA where climatology is very complex, the ideal would be to have an idea about the spatial variations of the ISO intensity and frequency, in order to better understand their influence on the climatic fields. It is therefore necessary to build a gridded datasets of daily or monthly ISOI and ISOP in order to investigate their spatio-temporal variations. The ISOI index mostly used by many authors in the past was the intraseasonal variance, generally obtained by applying a moving average filter on a given data time series [21].

The wavelet analysis is a mathematical technique which is very useful for numerical analysis and manipulation of multidimensional discrete signal sets. Its main characteristic is the introduction of the time-frequency decomposition. It is a very powerful tool for harmonic analysis, because unlike the classical analysis which allows just the transformation in time series from the time-space into the time-frequency space, the wavelet analysis is able determine both the dominant time scales of variability and how they vary with time [22, 23]. Unlike the moving average that gives the average variance on a chosen frequency band, the WA gives the intraseasonal variance as a function of frequency and time. From the wavelet spectrum obtained from a time series, it is possible identify for each time and each frequency, the value ISO the variance itaken here as ISO intensity corresponding to this frequency.

In this paper, we applied wavelet analysis on the daily Outgoing Long-wave Radiation (OLR) data to extract the intensity and frequency of intraseasonal oscillations in Central Africa. The paper is organized as follows: in the next section, the data and method of analysis will be described. Section 3 will present the main results obtained and their analysis. Finally, Section 4 is devoted to a few discussions and conclusions.

\section{Data and Methods}

\subsection{Data}

The rainfall proxy, used in this study is the daily Outgoing Longwave Radiation (OLR) at $2.5^{\circ} \times 2.5^{\circ}$ latitude-longitude resolution $[7,24]$. In the tropics, surface temperatures varies modestly trough the annual cycle, the strongest variation in the OLR result from changes in the amount and depth of clouds. This direct physical connection with clouds led many authors to the use of OLR in quantitative precipitation estimation in some geographical regions around the world [25-27]. The linear relationship OLR-rainfall allows the use of OLR data in place of gauge observations or as supplement to gauge observations, especially in climate variability studies in the tropics. The OLR datasets are available on the NOAA website https://www.esrl.noaa.gov/psd/data/gridded/data.interp_OLR. html and can be freely downloaded.

\subsection{Methods}

To extract the ISOP and ISOI in CA, we applied wavelet analysis on 25-70-day filtered OLR time series for the period 1981-2015. Filtering a time series consists in isolating useful frequencies and attenuating the unwanted frequencies or noise. The filtering technique used in this study is the Lanczos filter [28]. Its main advantage is the reduction of Gibb's oscillation [29].

As stated above, unlike the classical Fourier analysis which allows just the transformation of time series from the time-space into the time-frequency space, the wavelet analysis is able determine both the dominant time scales of variability and how they vary with time [22, 30, 31]. For a discrete sequence $x(n)$, the wavelet transform $W_{n}(s)$ is defined as the inner convolution of $x(n)$ with a scaled and translated version of $\psi(t)$. 


$$
W_{n}(s)=\sum_{n^{\prime}=0}^{N-1} x_{n^{\prime}} \psi^{*}\left[\frac{\left(n^{\prime}-n\right) \delta t}{s}\right]
$$

Where $s$ is the "dilation" parameter used to change the scale, and $\mathrm{n}$ is the translation parameter used to slide in time. $\delta$ t is the constant time interval between two consecutive values. $\Psi(t)$ is the Wavelet function. Wavelet functions have many kinds, but in this study we used the Morlet wavelet which has better local character both in time domain and in frequency domain [31]. The asterisk $(*)$ denotes complex conjugate. Then By varying the wavelet scale $s$ and translating along the localized time index $\mathrm{n}$, one can plot an image representing both the amplitude at any scale and how this amplitude evolves with time.

To study the characteristics of ISO (ISOP and ISOI), our original time series was first subjected to bandpass Lanczos filter with cut-off frequencies $1 / 70$ day $^{-1}$ and $1 / 25$ day $^{-1}$. After the filtering, the wavelet transform was applied to our 25-70day filtered data obtained, and we used the wavelet spectrum to extract the ISOP and ISOI. By this method for each grid point in the study area, we calculated the wavelet variance spectrum and identified for each day the maximum variance. The period exhibiting that maximum variance is the ISOP and the value of the variance is the ISOI. By this algorithm we have built the daily ISOP and ISOP datasets, with the same dimensions as the original time series. Since the wavelet variance obtained ranged from 0 to about 20000 $\mathrm{W}^{2} / \mathrm{m}^{4}$, we opted to normalize the ISOI time series in order to the range (scale). For each grid point, we took the deviation from the long-term mean in the units of standard deviation. For a given original time $\operatorname{series} x$, the normalized time series $*$ is calculated as:

$$
x=\frac{x-\bar{x}}{\sigma}
$$

Where $x$ the mean, and $\sigma$ the standard deviation of the original data time series.

\section{Results}

\subsection{ISO Intensity Variations}

Figure 3 shows the seasonal mean ISOI indices averaged within our study period. In this figure one can observe that the ISO activity is highly seasonal, as ISOI peaks during December-May and minimizes during June-November. It is also revealed in this figure that the ISO activity is cyclical throughout the year. In fact in DJF, a zone of high positive ISOIs (red color) is observed, which covers almost the entire Congo Basin and extends until the Indian Ocean on East Africa borders (southwestern Tanzania). The ISOIs then decrease progressively (MAM), giving chance to negative values in JJA and SON. Near the center and around this zone, one can see that the ISO activity evolves the opposite way, that is, the ISO activity at the center and around is high during December-May and lower during June-November. Further investigations are needed to clearly explain this observation because the present study we focused on the general aspect. In Table 1 are summarized the statistics of the ISOI for each of the four seasons. Figure 4 shows the day-today variations of the ISOI indices over WCA and ECA, within the period 1981-2015. It can clearly be seen on this figure that the ISO strength undergoes severe changes from day to another. The long-term average normalized daily ISO intensity ranges between -0.8 and 2.6. A peak of ISO activity is observed at the beginning and end of the year (DecemberMay). There are some years with very high signal such as $1980,1985,1990$ and the years of very low signal such as 1982, 1984, 1994, and 2001. Many studies done on the variations in the ISO characteristics have been made on a global scale. Generally the authors associated to the entire globe or region a single index to describe the variations of the intraseasonal oscillations. The advantage of the present study is that it makes it possible to associate with each grid point an index, making it easier to study the spatio-temporal variations of ISO activity.

\subsection{ISO Period Variations}

Many authors who attempted to study ISOs in the tropics focused only on the ISO intensity. But the investigation of ISO activity also in terms of frequency will be of great importance in the modeling task, especially over CA where the climate features sometimes exhibit abrupt change within few kilometers. The investigation of the ISO frequency might be used to develop a method by which the frequency of oscillations should be set. The ISOP indices are computed here using the method described in the previous section, that is, the ISOP is the period corresponding to the maximum variance. Figure 5 shows the seasonal mean ISOP in CA. The seasonality of ISO periods is clear, showing two seasons of long ISOP (DJF and JJA), intercepted by two seasons of short ISO (MAM and SON). It is also noticeable that the ISOP seems to be longer in Eastern CA when compared with western CA. In Table 2 are summarized the statistics of the ISOP for each of the four seasons. In Figure 6 is displayed the day-to-day variations of ISOP indices in WCA and ECA during 1981-2015. This figure reveals the strong variations in the ISO with years of longer oscillations such as 1985 and 1999, and years of shorter oscillations such as 1987 and 1992. The daily ISOP indices are ranged between 38-49 days. It can also be confirmed that the oscillations appeared to be longer in ECA, when compared with WCA.

\section{Summary and Conclusions}

The goal of this study was to use the wavelet transform to compute the intensity and frequency of 25-70-day intraseasonal atmospheric oscillations in Central Africa. To achieve this goal, we applied discrete wavelet transform on $2.5^{\circ} \times 2.5^{\circ}$ daily OLR datasets for the period 1981-2015 (35 years). After filtering the original datasets, the wavelet transform was applied to the 2570-day filtered datasets obtained, and for each day the maximum variance is taken as ISOI index and the period exhibiting that maximum variance is the ISOP index.

The plot of seasonal mean normalized ISOI showed that 
the highest ISOIs are generally observed during DJF and MAM, while the low ISO are observed during JJA and SON. The plots of yearly mean ISOIs revealed that the ISOI undergoes strong year-to-year variations with years of very high amplitude and years of lower ISOIs. Globally the ISOI decreased for decade to another, with the highest values during 1981-2010, and the lowest values during the recent years (2010-2015). For the ISOP, the peak periods are obtained during MAM and JJA. But for the four seasons the daily periods are mostly ranged between 40-50 days, suggesting the dominant MJO signal. The plot of yearly mean ISOP also show strong interannual variations for all the four seasons. Further studies are necessary to deeply investigate the physical process that induce the variations of ISOP and ISOI in CA, and it will then allow researchers to improve the parameterization of ISO processes in CA, for the good use in regional climate models.

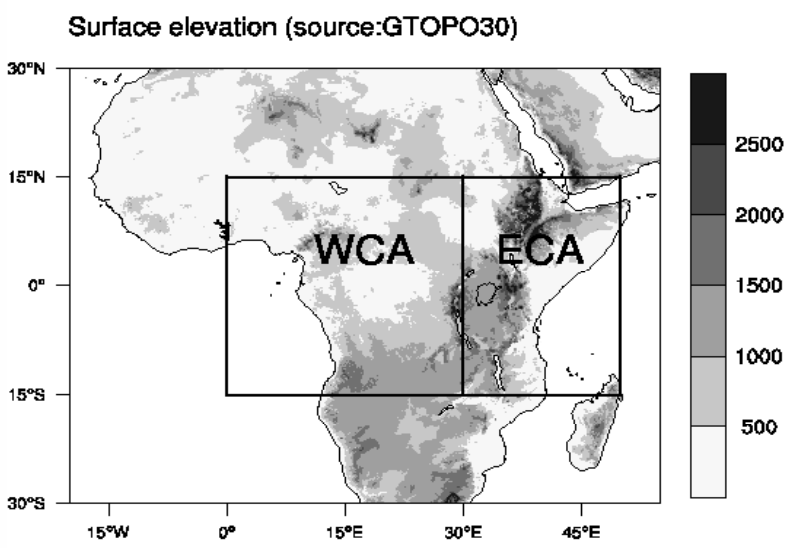

Figure 1. Topography of the study area based on 30-min topographic data (meters) from Digital Elevation Model (DEM) of the US Geological Survey. The $W C A\left(15^{\circ} \mathrm{S}-15^{\circ} \mathrm{N}, 0-30^{\circ} \mathrm{E}\right)$ and $\mathrm{ECA}\left(15^{\circ} \mathrm{S}-15^{\circ} \mathrm{N} 30^{\circ} \mathrm{E}-50^{\circ} \mathrm{E}\right)$ are shown as solid boxes.

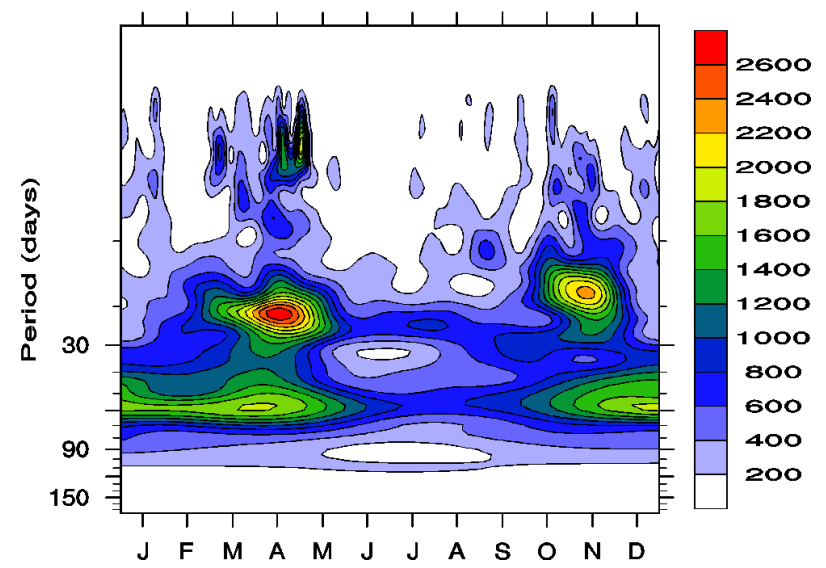

Figure 2. Wavelet spectra of the OLR anomalies averaged over Central Africa. A 120 days cut off high pass filter was applied to long term anomalies in order to remove any aspect of seasonal cycle and interannual variability.

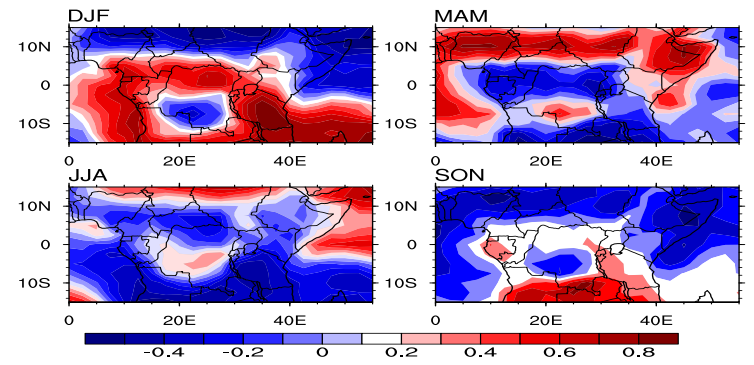

Figure 3. Seasonal mean ISOI in CA averaged within 1981-2009. The values are dimensionless since the ISOI field is normalized, and the corresponding season is indicated at the left top of each plot.

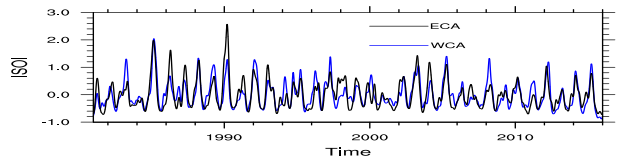

Figure 4. Daily variations of the ISOI indices for WCA and ECA within the period 1981-2015. The values are dimensionless since the ISOI field is normalized.

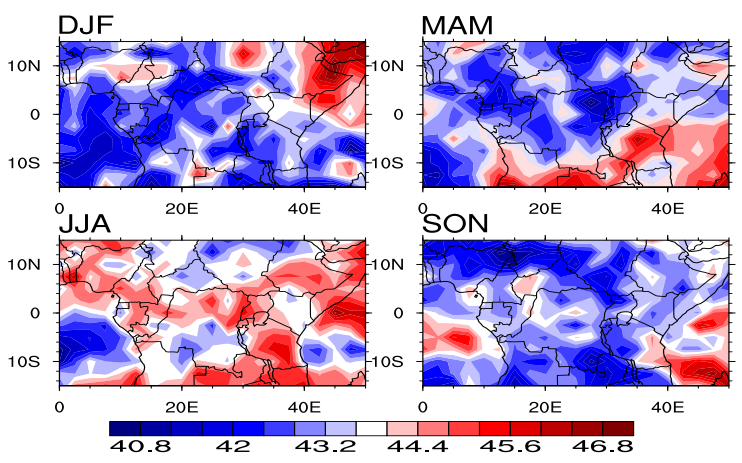

Figure 5. Seasonal mean ISOP within the study period. The periods are in days and the corresponding seasons are indicated at the left top of each plot.

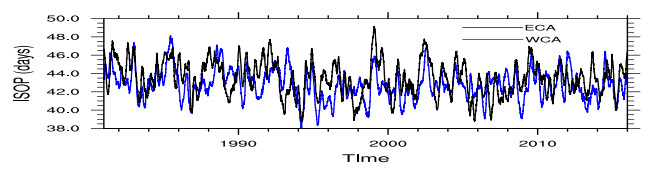

Figure 6. Daily variations of the ISOP indices for WCA and ECA within the period 1981-2015. 
Table 1. Statistics of the seasonal mean ISOIs (normalized values) over CA within the study period.

\begin{tabular}{llllll}
\hline Season & Mean & Standard deviation & Minimum & Maximum & State \\
\hline DJF & 0.21 & 0.41 & -0.89 & 1.85 & Above-normal \\
MAM & 0.39 & 0.44 & -0.65 & 1.81 & Above-normal \\
JJA & -0.30 & 0.18 & -0.76 & 0.61 & Below-normal \\
SON & -0.22 & 0.23 & -0.71 & 0.59 & Below-normal \\
\hline
\end{tabular}

Table 2. Statistics of the seasonal mean ISO periods (in days) in CA, averaged within the study period.

\begin{tabular}{lllll}
\hline Season & Mean & Standard deviation & Maximum & Minimum \\
\hline DJF & 45.11 & 2.27 & 50.65 & 40.96 \\
MAM & 44.01 & 1.97 & 39.01 & 48.73 \\
JJA & 46.45 & 2.44 & 53.17 & 43.22 \\
SON & 44.33 & 2.12 & 39.32 & 50.9 \\
\hline
\end{tabular}

\section{Conflict of Interest}

The authors declare no conflict of interest.

\section{Acknowledgements}

The NCAR/NCEP reanalysis data was provided through the NOAA Climate Center http://www.cdc.noaa.gov. Most of the scripts used in this study were produced from the NCL website http://www.ncl.ucar.edu.

\section{References}

[1] Thomas, M.; John, C. H. C.; Alexander, G.; Nicolas J. C. Temporal precipitation variability versus altitude on a tropical high mountain: Observations and mesoscale atmospheric modeling. Q. J. R. Meteorol. Soc. 2009, 135, 1439-1455.

[2] Vondou, D. A; Nzeukou, A.; Lenouo, A., Mkankam, K. F. Seasonal variations in the diurnal patterns of convection in Cameroon-Nigeria and their neighboring areas. Atmos.sci. Let. 2010, 11, 290-300.

[3] Moore, A.; Ioschnigg, J.; Webster, P.; Leben, R. Coupled ocean-atmosphere dynamics in the Indian ocean during 19971998. 2010, J. climate, 401, 356-360.

[4] Mutai, C.; Hastenrath, S.; Polzin, D. Diagnosing the 2005 drought in equatorial east Africa. J. Climate, 20, 4628-4637.

[5] Mitchell, T. P.; Wallace, J. M. The annual cycle in equatorial convection and sea surface temperature. J. Climate, 1992, $1140-1156$

[6] Tsuneaki, S. Seasonal variation of the ITCZ and its characteristics over central Africa. Theor. Appl. Climatol, 2011, $103,39-60$.

[7] Gruber, A.; Krueger, A. F. The status of the NOAA outgoing longwave radiation data set. Bull. Amer. Meteor. Soc, 1984, $65,958-962$.

[8] Huffman, G. J., Bolvin, D. T. Version 1.2 GPCP One-Degree Daily Precipitation Data Set Documentation. Mesoscale, Atmospheric Processes Laboratory, NASA Goddard Space Flight Center, 2013.
[9] Kummerow, C., W. Barnes, T. Kozu, J. Shiue, and J. Simpson. The Tropical Rainfall Measuring Mission (TRMM) Sensor Package. Journal of Atmospheric and Oceanic Technology, 1998, 15, 809-817.

[10] Blacutt, L. A., D. L. Herdies, L. G. G. de Gonçalves, D. A. Vila, and M. Andrade. Precipitation comparison for the CFSR, MERRA, TRMM3B42 and Combined Scheme datasets in Bolivia. Atmos. Res, 2015, 163, 117-131.

[11] Madden, R. A.; Julian, P. R.; Observations of the 40-50 day tropical oscillation: A review. Mon. Wea. Rev., 1994, 122, 814-837.

[12] Jury, M. R.; Mpeta, J. Intraseasonal convective structure and evolution over tropical East Africa. Climate Res., 2010, 17, 83-92.

[13] Maloney, E. D.; Jeffrey, S. Intraseasonal Variability of the West African Monsoon and Atlantic ITCZ. J. climate, 2008, 21, 2898-2918.

[14] Tchakoutio, A. S.; Nzeukou, A.; Tchawoua, C. Intraseasonal atmospheric variability and its interannual modulation in central Africa. Meteorol Atmos Phys, 2012, 117, 167-179.

[15] Camberlin, P. and Pohl, B. Influence of the Madden-Julian Oscillation on east African rainfall. Part I: Intraseasonal variability and regional dependency. Int. J. climatol, 2006, 132, $2521-2539$

[16] Janicot, S.; G. Caniaux, F.; Chauvin et al. Intraseasonal variability of the West African monsoon. 2011, Atm. Sci. Lett, $12(1), 58-66$.

[17] Tchakoutio, A. S.; Nzeukou, A.; Tchawoua, C.; Kamga, F. M.; Vondou, D. A comparative analysis of intraseasonal variability in OLR and 1DD GPCP data over central Africa. Theor. Appl. Climatol, 2013a, 116, 1 (2), 37-49.

[18] Tchakoutio, A. S.; Nzeukou, A.; Tchawoua, C.; Sonfack, B.; Siddi, T. Comparing the patterns of 20-70 days intraseasonal oscillations over Central Africa during the last three decades. Theor. Appl. Climatol, 2013b, DOI: 10.1007/s00704-0131063-1.

[19] Jury, M. R., Tazalika, L. Intra-seasonal rainfall oscillations over central Africa: space-time character and evolution. 2008, Theor. Appl. Climatol, 94, 67-80.

[20] Wheeler C. M.; Hendon, H. H. An all-season real-time multivariate MJO Index: Development of an index for monitoring and prediction. Mon. Wea. Rev., 2004, 132, 19171932. 
[21] Jones, C.; Carvalho, L. M. V. Stochastic simulations of the Madden-Julian oscillation activity. Clim. Dyn, 2011, 36, 229 246. DOI 10.1007/s00382-009-0660-2.

[22] Torrence, C.; Compo, G. P. A practical guide to wavelet analysis. Bull. Amer. Meteor. Soc., 1998, 79: 61-78.

[23] Daubechies, I. The wavelet transform time-frequency localization and signal analysis. IEEE Trans. Inform. Theory, 1990, 36: 961-1004.

[24] Liebmann, B.; Smith, C. A. Description of a Complete (Interpolated) Outgoing Longwave Radiation dataset. B. Am. Meteorol. Soc, 2001, 77, 1275-1277.

[25] Arkin, P.; Richards, F. On the relationship between satelliteobserved cloud cover and precipitation. Mon. Wea. Rev, 1981, 109, 1081-1093.
[26] Arkin, P. A.; Meisner, N. The relationship between large scale convective rainfall and cold cloud over the Western Hemisphere during 1982-1984. Mon. Wea. Rev, 1982, 115, 51-74.

[27] Arkin, P. A.; Xie, P. Global monthly precipitation estimates from satellite-observed Outgoing Longwave Radiation. J. Climate, 1997, 9, 840-858.

[28] Lanczos, C. Applied Analysis. Prentice-Hall, 1956, 539 pp.

[29] Duchon, C. E. Lanczos filtering in one and two dimensions. J. Appl. Meteor. 1979, 18, 1016-1022.

[30] Chao, B. F.; Naito, I. Wavelet analysis provides a new tool for studying Earth's rotation. 1995, EOS., 76: 161-165.

[31] Lee T. L. D., Yamamoto, A. Wavelet Analysis: Theory and Applications. 1994, Hewlett Packard Journal, 44-52. 